\title{
La terquedad de una teología. Cambio social y pensamiento cristiano en América Latina*
}

\author{
F. Javier Vitoria Cormenzana \\ Instituto Diocesano de Teología y Pastoral, Bilbao.
}

Del 29 de junio al 4 de julio se celebró en San Lorenzo del Escorial el II Encuentro internacional, Cambio social y pensamiento cristiano en América Latina. Un intervalo de veinte afios lo separaba del primero. Los grandes acontecimicntos históricos vividos en el mundo desde entonces y los cambios sociales y eclesiales ocurridos en el continente latinoamericano propiciaron esta segunda oportunidad. Se trataba de escuchar de viva voz los retos con los que se en[renta el pensamiento cristiano liberador, y de presentar sintéticamente sus nuevas trayeclorias, las mediaciones culturales más influyentes que utiliza y las repercusiones que está teniendo no sólo en América, sino en Europa, Asia y Alrica.

Con cstos objetivos la entidad organizadora, el Instituto Fe y Sccularidad, creó un espacio para el intercambio sosegado. Más de doscientas personas interesadas en el tema se hicieron presentes en él. Teólogos/as de la liberación, expertas/os en pensamiento cristiano y creyentes de diversas latitudes, vocaciones e iglcsias compartimos cuatro apretadas jomadas de trabajo, y celebramos conjuntamente la fe en la liberación alcanzada en y por Jesucristo, y la vida, supremo don del Dios de los pobres.

Las jormadas transcurrieron según el programa previsto. Solamente un cambio: las cinco áreas de trabajo por grupos' fueron incrementadas con dos más. Una específicamente teológica y para toólogos, y otra sobre el influjo de lo

* El presente artículo ofrece una crónica del II Encuentro Cambio social y pensamiento cristiano, celebrado en El Escorial, del 29 de jwnio al 4 de julio, y el siguiente, de J. I. Gonzáler. Faus, un resumen de las ponencias. La edjırial Trotla publicará a comienzos de 1993 todas las ponencias del Encucntro. 
femenino en cl pensamiento cristiano, que resultó multitudinaria.

Este trabajo no ticne la intención de realizar una crónica/balance de las jornadas. Otros levantarán acta de lo que allf sucedió de manera más fidedigna. Tampoco pretende dialogar con las propuestas teológicas que allí se hicieron. Tiempo habrá para hacerlo, cuando se publiquen las actas del encuentro. Su deseo es más modesto. Pretende dar cuenta, pocos meses más tarde, de los recuerdos más vivos de lo que allí se escuchó, y ofrecer algunas reflexiones susciladas por cllos. El resultado de su percepción no puede ser latinoamericano. La escucha sc ha realizado desde este otro lado del Atlántico, desde una sociedad española que pisa el acelcrador para alcanzar ese modclo de modemización y progreso, que postula la cultura de la satisfacción de los privilegiados del norte ${ }^{2}$. Pcro pucde garantizar que le asistía la convicción de que desde "las venas abicrtas de América Latina" llcgan propuestas salvíficas para esta sociedad, que, precisamente, pone en peligro sus falsas necesidades y sus intereses injustos.

Antes de pasar más adclante, tres observaciones. Resultó notoria la auscncia de la Iglesia cspañola y de tcólogos de algunas de sus faculbades, y excesiva la presencia de jesuilas en las ponencias. La intervención más aplaudida fue la del obispo auxiliar de Sao Paulo (Brasil), Antonio Celso Queiroz, que clausuró las jornadas. La de Johann Baptist Metz pecó de "eurocentrismo" en su forma. Mientras la mayor parte del público leía en la sala su versión castellana, el teólogo, "impasible el ademán", daba lectura a la alemana. Resultaba difícil imaginar que en un encuentro centroeuropco toleren algo parecido a un teólogo latinoamericano.

\section{Una teología que ya tiene historia}

Hace veinte años el 1 encucntro internacional ${ }^{3}$ supuso de hecho, aunque no lo pretendicse directamente" , "la presentación en sociedad de la teología de la liberación”. Así nos lo recordó Alfonso Alvarez. Bolado en cl acto de presentación de éste.

Esta vez giró premeditada y abiertamente en tomo al tema de la teología de la liberación. Esta, pese a quien pese, se ha convertido en la única corricnte de pensamiento cristiano original que se produce en aquel continente, y consecuentemente la que ocupa el centro del intcrés tcológico. La libcración no es lamentablementc hegemónica en América Latina, pero sí su teología. Las demás se definen frente a clla. Si no fuera por esta confrontación resultarian irrelevantes en el conjunto del pensamiento cristiano. Son puro reflejo de lo que ya circula -y además mcjor- por Europa y Estados Unidos.

Desde sicmpre el saber tcológico había sido patrimonio exclusivo de los centros universitarios curopcos Ningún aporte teológice scrio se podía esperar

Universidad Centroamericana José Simeón Cañas 
de Latinoamérica, que constitula para los teólogos europeos una especie de "Galilea de los gentiles" de la que nada realmente bueno podria salir. Sin embargo, el año 1972 esta lógica se quebró definitivamente. En el congreso del Escorial, la ponencia de Gustavo Gutiérrez "representó el polo referencial" para la "Iamilia de opciones" allí presente", y proclamó en Europa la buena nolicia y los desafios de la teología de la liberación" como "voz que clama en cl desicrto... preparen los caminos del Señor...".

El cronista oficial de aquellas jomadas describió aquel descubrimiento de la siguiente manera: "Y sentíamos el estremecimiento de que la voz Juera cierta y real y nosotros desierto. Por un momento Gustavo nos había hecho entrever que 'Latinoamérica' no era adjetivo, sino el dedo que indicaba un lugar de tránsito de la salvación. No un lugar mítico, ni mitificable, pero si un "lugar de discemimiento'... No se me entienda mal. No quiero decir que la ponencia de Gustavo Gutiérrez no sea una ponencia articulada, incluso minuciosamente y, por tanto, 'crilicable'. Pero en ella sucedia la toma de palabra, la libertad de hacer futuro de algo que tendrá historia, aunque tos textos de la 'Leología de la liberación' fueran desmontados por una crítica sagaz y evitadora de confliclos, y aunque la mayor parte de los hombres de esta 'Tamilia de opciones' fueran un día reducidos al silencio".

Estas palabras contienen todo el lirismo y el entusiasmo que encierra el corazón generoso de su autor. Pero el paso del tiempo las descubre sobre todo proféticas. Aquella toma de palabra y aquella libertad uenen hoy una historia que puede rastrearse.

La ponencia de Joao B. Libanio, Panorama de la teología de América Latina en los 20 últimos años, desgranó las características de sus diversos períodos. Repasó cumplidamente la constitución y sistematización de su método, su confrontación paulatina con diversos análisis socio-políticos de la realidad social' ${ }^{9}$ y su singular proceso de expresión sistemática de la le cristiana. Además la comunicación de Antonio González, Significado filosófico de la teología de la liberación, puso de manifiesto cómo la trayectoria de un pensamiento que hace de la praxis histórica el punto de partida y el criterio fundamental de verificación del quehacer teológico, ha supuesto un cambio de paradigma u horizonte intelectual en la actividad teológica.

Juan Luis Segundo analizó las crílicas que le llegaron desde las dos instrucciones de la Congregación para la Docturina de la Fe. También realizó una autocrítica sincera, libre y penetrante sobre la que convendrá volver algún día. En ella, entre orras cosas, señaló la dificultad que su condición de teología pastoralizada plantea para dialogar y enriquecer otras teologlas de marcado sello académico.

Sin embargo, la teología de la liberación ha demostrado su fecundidad más Digitalizado por Biblioteca "P. Florentino Idoate, S.J."

Universidad Centroamericana José Simeón Cañas 
allá de las fronteras del continente latinoamericano. Varias intervenciones dejaron constancia del hecho. J. B. Metz se relíió a la invitación, cursada a la teología europea, para participar en una doble despedida: el adiós de la teología a su inocencia social y política y el adiós a su inocencia cultural y ćtica, es decir, al eurocentrismo que tiene interiorizado. José Ignacio González Faus, en su ponencia resumen del encuentro, señaló cómo había engendrado una hermana menor, la teología de la marginación ${ }^{10}$ al servicio del "cuarto mundo" de los paises desarrollados. Jordi Gispert-Sauch presentó la(s) propuesta(s) de teología asiática de la liberación, en un contexto social y religioso en el que a la experiencia de pobreza e injusticia se antade la experiencia de la debilidad social y humana. Y finalmente Julio Lois hizo lo mismo en relación con los proyectos africanos para los que la articulación interfecundante de las perspectivas antropológico-cultural y económico-política va adquiriendo especial relieve.

\section{Una teología que va haciendo historia}

Más importante que estas consideraciones resulta poder afirmar que, en estos veinte años, la tenlogía de la liberación ha construido historia. Desde su propio estatuto epistemológico, ha contribuido a abrir futuro a la esperanza de unos hombres y mujeres, cuyo presente parcce querer condcnarlos cada vez más a ser masa sobrante. Ella constituye, como recordaba González Faus, la más importante versión moderna de "teología apofática" que cuestiona al dios inconfesado del occidente sin utopias. Su condición de intellectus amoris la convierte en la corriente de pensamiento actual más cálidamente comprometida con lo humano, y más abiertamente enfrentada a ese "conocimiento sin amor", característico de las sociedades tecnocráticas actuales, que condena a los pobres a la miseria y la muerte. Seguramente no hay mejor argumento en favor de esta a advertir, como hicieron José Comblin y Victor Codina, que los neoconservadores norteamericanos han querido contrartestar sus efeclos elaborando una teología justificadora del capitalismo.

Sin embargo, es posible tracr aquí otro tipo de argumentos. Son bien conocidos su acompañamiento a los católicos presentes en el sandinismo, su contribución a los procesos de pacificación salvadoreffos o su servicio al encuentro entre el régimen cubano hostil a la religión y la Iglesia. Sobre bodo su gran empeño en acompafiar, discernir y analizar teológicamente la vida de las comunidades de base desde la perspectiva de los pobres. Ronaldo Muñoz con su ponencia, Experiencia popular de Dios y de la Iglesia, dejó constancia práctica y sapiencial dc este esfuerzo. El mismo monseñor Queiroz reconoció que su aporte resultaba imprescindible para la Iglesia latinoamericana en marcha hacia el futuro.

Todo ello la convierte en un hecho eclesial de primera magnitud en este final del siglo XX. Pertrechada con la virtud cristiana de la terquedad, no ha defraudado las expectativas creadas hace una keintena de años. Se ha holgado con los

Universidad Centroamericana José Simeón Cañas 
pobres, ricos en historias memorables que ocurren en el diario quehacer de un pueblo que lucha por su derecho a la vida y por su derecho a proclamar el reino. Mantener viva y peligrosamente su memoria ha sido el mejor antídoto para no entramparse en los problemas y sufrimientos realmente dolorosos que han vivido sus autores, o en los márgenes y limitaciones que se les quicren imponer.

Allí, donde late el pulso de la historia, junto al tuteo cotidiano de los pobres con la muerte encontró su inspiración y su camino. El pueblo crucificado fue el signo principal de los tiempos, que ella percibió y escrutó atentamente para propiciar su liberación. Participando de su destino histórico, a través de la persecución e incluso del morir mártir de algunos de sus teólogos, experimentó "los costos" de una metodología teológica que hace de la liberación y el martirio y de su mutua relación "hechos mayores", desde donde relce las fuentes de la revelación y comprueba que éstas dan de sí cosas novedosas e importantes. Y así vivió su "propia pascua": el paso de una teología sólo de la liberación a una teología del martirio.

\section{El futuro de la teología de la liberación}

Libanio califícó la situación actual de la teología de la liberación como de revisión. Hasta ella la ha conducido un factor temporal: los cambios sociales y eclesiales vividos en las dos últimas décadas. Tampoco en América Latina ha ocurrido, ni a nivel político, ni a nivel eclesial, lo que se pensaba hace veinte años. Pero también un factor especial: sus propias perspectivas analíticas, hermenéuticas y epistemológicas se han ampliado, miran hoy más lejos que hace veinte años"

3.1. La crisis de un modelo de civilización: la pertinencia de la injusta realidad de la dependencia

La teología de la liberación fiel a sí misma se confronta realistamente con las nuevas circunstancias sociales y eclesiales, que tanto a nivel mundial como latinoamericano han dispuesto los cambios sociales.

Intentar la descripción de la realidad social de Latinoamérica resulta complejo y muy laborioso, dada su diversificación. Pero esta dificultad aumenta, cuando además se quiere explicar con rigor sus causas. La historia política y social de los ochenta parece haber precarizado irremediablemente la principal mediación socioanalítica que la teología de la liberación ha utilizado. Concretamente, se estima que la teoría de la dependencia ha quedado desautorizada por insuficiente para explicar los cambios socio-políticos, vividos por Latinoamérica en el último decenio. No existe un único proceso estructural que los haya detcrminado en su conjunto y que consecuentemente los explique satisfactoriamente. Se hace necesario aprender a utilizar mediaciones más complejas para rcalizar los análiDigitalizado por Biblioteca "P. Florentino Idoate, S.J."

Universidad Centroamericana José Simeón Cañas 
sis adccuadamente.

Dos intervenciones complementarias, que no debieron programarse con cuarenta y ocho horas de distancia entre sí, dicron cuenta de algunas tendencias significativas de las transformaciones acaecidas en los dos últimos decenios. Los cambios políticos-sociales en América Latina de 1972 a 1992 fueron analizados por el chilcno Migucl Antonio Garretón. El rector de la UCA nicaragüense, Javier Gorostiaga, disertó sobre la mediación de las ciencias sociales y de los cambios internacionales. Ambas, aunque con diferentes perspectivas, contenidos, acentos y talantes, coincidieron en una tesis central: la década de los ochenla es una década perdida para el desarrollo y ganada para la democracia política.

El modelo de desarrollo económico, que llevaba inscrito en su seno la teoría correspondiente entre crecimicnto económico y bienestar social, se ha derrumbado. La pobreza ha crecido geométricamente a nivel mundial. Los últimos informes mundiales señalan que la pobrcza se amplía en términos absolutos y relativos. Más en concreto, América Latina es hoy más pobre que al comienzo de los ochenta. Existe una inmensa mayoría de su población lan empobrecida que cristianamente ya no tenemos ni nombre que ponerle. $Y$ las perspectivas de futuro no son mejores. La concentración y centralización del poder mundial, la revolución tecnológica que ha hecho de la intensidad del conocimiento el factor decisivo de esa acumulación de poder y las transformaciones políticas globales ${ }^{12}$ así parecen augurarlo.

Pero no todo son mermas y callcjones sin salida. La democracia ha sido ganada dolorosamente en la mayor parte de los paises latinoamericanos. En realidad se trata de una democracia que, enmascarada, oculta su rostro verdadero. Sus figuras reciben los nombres de tutelada, baja intensidad, restringida, fachada. Encubren la crisis de gobemabilidad que la emergente sociedad civil plantea a una democracia apática antc cl sufrimiento de las mayorías populares, y sin base material para sustentar precisamente sus aspiraciones democráticas.

A pesar de todo, su existencia debe considerarse una conquista valiosa e irrenunciable. Sólo en democracia es posible responder adecuadamente a los retos con los que se enfrenta el presente y el futuro latinoamericano. Ella puede constituirse en el gran instrumento de lucha contra la pobreza, a condición de que sea efectiva y deje de ser irrelevante. ¿Para qué sirve una democracia que no resuelva efectivamente el problema más acuciante: la pobreza? ¿Qué puede significar la democracia, cuando las decisiones sobre la redistribución de la riqueza son tomadas por poderes fácticos sin control democrático?

El mayor obstáculo para resolver esta cuestión de la efectividad de la democracia de los países del sur es el norte. Sus políticas neo-liberales niegan de hecho la intervención de los diferentes agentes sociales. Su monopolio planetario del pensamiento y de la tecnología ha dado lugar a un mercado cada

Digitalizado por Biblioteca "P. Florentino Idoate, S.J."

Universidad Centroamericana José Simeón Cañas 
vez más adminisırativo y menos libre, que constituye la expresión mercantil de una dominación invisible y de un poder opaco. Y linalmente, su modelo de civilización no cs universalizable a todos los seres humanos. Se produciría un suicidio colectivo si las pautas de desarrollo del norte fuesen implementadas por cl sur. El norte lo sabe, y por ello impone en los países pobres un "darwinismo económico", que excluye a las mayorías para que csta civilización de la satisfacción de unos pocos pucda sobrevivir. Siguc en vigor, por tanto, la realidad de la dependencia, aunque ya no lo esté su teoría.

La solución a esta auténtica crisis de civilización sólo podrá venir desde las prioridades de "la agenda" del sur y no desde las del norte. Pero toda propuesta de solución, basada cn la existencia de un único sujeto capaz de uransformar la historia, ha de ser calificada de neo-fundamentalismo y se convierte en espúrea como la ncolibcral. El último decenio ha supuesto $\mathrm{cl}$ abandono de los modelos que la buscaban por la vía de la confrontación, y el lin de las vanguardias. El conflicto ha de ser procesado en el paradigma de la concertación y del consenso. Latinoamćrica reclama una descolonización de la imaginación y de la creatividad, que auspicie caminar sin claudicaciones hacia la construcción de la "nueva democracia mundial". Ello no será posible sin el surgimiento y la consolidación de una nueva matriz socio-política. No se parte de cero. La emergencia de la sociedad civil, la autonomia orgánica de los sectores socialcs, el descubrimiento del valor político de la cotidianeidad y de la irreductibilidad de la felicidad a términos de liberkad e igualdad son algunos de los frutos, todavia inmaduros, que cosecharon los ochenta. El reforzamiento de la diversificación de los actores sociales que, en distancia con los partidos, construyan la historia, y la potenciación del sistema de representación y de la capacidad redistributiva del Estado son algunas de las direcciones indicadas para cumplir con una ley inexorable del momento presente: los tiempos de la protesta sin propuesta han pasado.

\subsection{La incertidumbre de la Iglesia de los pobres}

Durante la úlima década la Iglesia de los mártires de América Central ha sido el paradigma de la Iglesia latinoamericana. Esta vive hoy tiempos de esperanza crucificada por la ambiguledad de su presente y el desconcierto ante su futuro. Las causas de los cambios de la Iglesia latinoamericana, desde Puebla a Santo Domingo, son muy diversas, y fueron analizadas por J. Comblin.

Algunas de ellas arrancan de la misma asamblea de Puebla. Su texto es ambigüo $y$, aunque entonces prevaleció la tesis de que estaba en continuidad con Medellín, hoy se constata un auténtico conflicto de interpretaciones en torno a él. Esta situación viene agravada por la estralegia involucionista de la Iglesia romana. Los nuevos obispos, los nuevos seminarios, el intervencionismo en la Confederación Latinoamericana de Religiosos y Religiosas y el Consejo Episcopal Latinoamericano y la beligerancia romana en el debate de la teología Universidad Centroamericana José Simeón Cañas 
de la liberación favorecen una leclura de Medellín y Puebla desde la clave de la restauración eclesiástica. La ascensión de los nuevos movimientos como el Opus Dei, renovación carismática, catccumenales, focolari, elc., ponen las bases para una nucva "colonización" de la Iglesia latinoamericana.

Pcro hay tambićn nuevas realidades sociales que contribuyen a la inceridumbre. Algunos recientes [enómenos sociales, como las nuevas masas populares marginales, despolitizadas y acumuladas en las nuevas magápolis, la pérdida de la religión popular por la influencia de la cultura de masas que llega a través de la tclevisión, el debilitamiento de los objetivos de la lucha social y política tradicional, plantcan una crisis cualitativa en los programas de evangelización liberadora de la Iglesia de los pobres. La vuclea de la democracia obliga a repensar de manera nueva la cuestión de la presencia pública de la Iglesia y de la influencia social de las comunidades cristianas de base.

\subsection{La teologia de la liberación ante su futuro}

Ciertamente, la tcología de la liberación ticne ante sí tiempo nuevo. Su tarea se está enfrentando con una mayor complcjidad en su proceso intelectual, y encontrando una creciente resistencia intraeclesial por parte de la jerarquía y de las fuerzas conservadoras.

Pero no presenta ningún síntoma de revisionismo. Frente a una tcología de la inevitabilidad de "la religión mercantilista", sigue manteniendo su subordinación a la práctica liberadora, aunque sepa que no existe alternativa inmediata capaz de cambiar el mapa de la pobreza. Como recordó Jon Sobrino, lo especifico de los teólogos de la liberación no es haber puesto la liberación en el centro de su tcologia, sino haber hecho de ésta elemento de una vida dedicada a la liberación. Hacer teología de la liberación es una forma de confrontarse con la realidad. El día que no se pueda hacer icología, harán otra cosa para liberar. Esta radical opción la ha convertido en la teologia contemporánea que mejor ha conseguido impostar su discurso en lo soteriológico de la fe cristiana. Su servicio a la práctica liberadora constituye la mejor contribución a la misión evangelizadora de la Iglesia latinoamericana. Las víctimas de la injusticia se han convertido en el gran reparo frente a su pretensión de que el reino de Dios ha imumpido definitivamente en la historia. La teología de la liberación se ha tomado en serio esta crisis de realización histórica de la salvación escalológica alcanzada en y por Jesucristo. La evangelización no debe contentarse con la conversión de la conciencia personal y colectiva de los hombres. Necesita alcanzar, transformar desde dentro y "hacer nuevas" la actividad en la que ellos están comprometidos, su vida y sus ambientes concretos (cfr. Evangelii Nuntiandi, 18). Este imperativo la ha conducido, durante veinte afios, a buscar aquellas condiciones teórico-prácticas, que hacen posible pensar y, sobre todo, realizar y actualizar la salvación cristiana para las mayorias pobres. Hoy sigue empefiada Universidad Centroamericana José Simeón Cañas 
en retomar creativamente la utopia del evangelio para contribuir, desde su propio estatuto epistemológico, a su articulación en propuestas históricamente viables en favor de la liberación de los pobres.

Tampoco puede afirmarse impunemente que se encuentre a las puertas de una claudicante conclusión mística de su aventura teólogica, ni que los teólogos de la liberación hayan iniciado una retirada estratćgica de la socicdad a la mística. La tcología de la liberación como la fe latinoamericana no participa del desencanto del pensamiento occidental. Son otras sus raices. Su matriz está en el "reverso de la historia", en la vida del pueblo pobre. Su pasado está ligado a la imupción, a la presencia y al éxodo de los que siempre estuvieron ausentes del escenario de la historia. Su presente se vincula al abandono de discursos universalistas y genéricos sobre los pobres para permitir que aflore la diferencia. Influjos, como cl de lo femenino y el de las culturas populares indígenas, presentados respectivamente por Ivone Gcbara ${ }^{13}$ y por Diego Irartazaval, han resultado cada día más fecundos para la tcología de la liberación.

Su opción por los pobres no la ha fundamentado ni en los análisis que utilizaba, ni en la compasión humana que sentía por su dolor. Su sostén es de carácter teologal y cristológico. Los pobres son la perspectiva desde la que Dios mira la realidad y desde la que la juzga. El recordarlo siempre y no olvidarlo jamás depende, como señaló Carlos Bravo, de hacer memoria viva del Jesús histórico a través de su seguimiento. Esta práctica convierte la tcología de la liberación en tcología narrativa y, en delinitiva, provoca su empeño por articular salvación e historia hasta que ésta sea historia salvada.

El futuro de la teología de la liberación depende, como recordó Pcdro Trigo, de que siga siendo pensable algo así como la fuerza histórica de los pobres, aunque no sea pensarla como una energía que, desde el reverso de la historia, ponga en marcha una revolución socialista que cambic el mapa político y social de América Latina. Esa fuerza histórica se alimenta de la razón simbólica y no se ejercita en la política de modo privilegiado, sino en el ámbito de esa cotidianidad agónica'4 de los pobres, que genera solidaridad y recrea el tejido de la vida social. Actúa en la historia como fermento a largo plazo, como encrgía que juzga la calidad humana de cada cultura, y como dinamismo convocante de un sujeto más ecuménico, la internacional de la vida, que hace posible milímetro a milímetro la constitución de un universalismo verdaderamente humano y sin discriminaciơnes, a la medida del don mesiánico de la fratemidad abierla de los hijos de Dios. 


\section{Notas}

1. Las jomadas eran las siguientes: a) Repercusiones de la caída del comunismo del este europeo en la teología de la liberación; b) El cristianismo latinoamericeno frente a la hegemonia norteamericana; c) Los españoles y la promoción de la le y la América Latina contemporánea; d) Mapa de fuerzas convergente y divergentes en América Latina, especialmente dentro de la Iglesia catolica. Previsiones de futuro; e) Involución eclesiástica universal y pensamiento cristiano liberador.

2. Cfr. Galbraith, J. K., La culura de la satisfacción. Barcelona 1992.

3. Cfr. la publicación de sus aetas: Instituto Fe y secularidad, Fe cristiana y cambio social en América Latina. Encuentro del Escorial, 1972. Salamanca 1973.

4. Cfr. Alvarez, Bolado, A., Introducción, en /bid., Pp. 11-15; 23.

5. Por ejemplo, la conservadora, la neoconservadora, la carismálica, la de la reconciliación y las posiciones crítico/independientes.

6. Gutiétrez, G. , Evangelio y praxis de liberación, en /bid., pp. 231-245.

7. Cfr. Alvarez Bolado, A., Ibid., p. 27.

8. Aquel mismo año apareció en España la obra G. Gutiérrez, Teología de la Liberación. Salamanca (1972), que ha dado nombre a esta teología. Solamente un año antes se había publicado en Perú. Había en ella una incipiente y novedosa propuesta tcológica, que iba a terminar con el monopolio teológico europeo.

9. Libanio señaló los siguientes: teoría de la dependencia, idelogía de la seguridad nacional, tcoría de la trilateral, teoría de los mega-bloques y análisis post-marxistas. Esıa múltiple confrontación ha permitido llegar en la actualidad a un consenso sobre la liberación como realidad tcológicamente trabajable, el método inductivo (ver, juzgar y actuar), la (ceundidad del discemimiento de los signos de los tiempos y algunas verdades del marxismo.

10. Cfr. Sols Lucia, J., Teología de la marginación. Los nombres de Dios. Barcelona 1992.

11. El encuentro del Escorial vino a confirmar algo que ya había observado G. Gutiérez en la introducción de la 7" edición de su obra elásica; Cfr. "Mirar lejos", en Teología de la liberación. Perspectivas. Lima 1990, pp. 9-60; especialmente para esta cuestión pp. 16-24.

12. J. Gorostiaga señala las siguientes: el colapso del "socialismo real", la unidad Europea, Japón y la "era del Pacífico" y la crisis de la hegemonía norteamericana. Se puede encontrar parte de su ponencia en Sal Terrae, Julio/Agosto 1992, pp. 547-557; $c f r$. "El Este y el Sur: nuevo dilema global. Siete tesis para un argumento".

13. Esta ponencia provocó reacciones encontradas. Algunas de sus propuestas merecerán lecrse con atención, cuando se publiquen las actes del encuentro.

14. El concepto de cotidianidad agónica produjo un importante debate con P. Trigo. Debido seguramente a que nuestra expcricncia europea nos habla de un repliegue a la cotidianidadsalisfiecha que Bentera corponatiyismpinselidarioj." 